\title{
Science/Education Portraits V: The Scientific Tertiary Education that I had Envisioned
}

\section{Maurice HT Ling*}

Colossus Technologies LLP, HOHY PTE LTD, Singapore

*Corresponding Author: Maurice HT Ling, Colossus Technologies LLP, HOHY PTE LTD, Singapore.

Received: June 27, 2019; Published: July 11, 2019

DOI: $10.31080 /$ ASMS.2019.03.0350

\begin{abstract}
Current tertiary education system has been criticized as being outmoded and inadequate to address modern day needs. Incorporating the concept of stackable credentials, I propose a framework of seminar series and apprenticeship within the 4-year tertiary education system for science. Seminar series can replace teaching while apprenticeship can address the needs of education. Given that a typical undergraduate degree amounts to 2,000 hours, I demonstrate that a combination of seminar and apprenticeship can amount to 1,860 seminar hours and 1,000 apprenticeship hours, which is equivalent to 6 months of full-time employment. This can allow the student room to develop a competency-based portfolio.
\end{abstract}

Keywords: Yeast; Microbes; Plant

\section{The current tertiary education system}

I have a confession to make - I am not a good student. By all account, I am not a good classroom student. I did not do my physics and chemistry homework during my Secondary 3 and 4, in preparation for my GCE 0 Level examination. I challenged my teacher to select any 10 questions from the 10-Year Series (a compilation of GCE 0 Level examination questions for the preceding decade); if I can answer those questions and maintain more than $80 \%$ for my tests, do not ask me for my homework as they are a waste of my time. This became my secret agreement with my teacher as she never bothered me again. I questioned my teacher when I was 10 years old when she told us that a coconut is a seed, for which I search for a coconut seed and showed it to her. I slept for most of my tertiary classes and up to $80 \%$ of my undergraduate lectures. I purposely oversleep and missed the last lecture in my undergraduate just for the heck of it. I completed my computing degree while I was doing my $\mathrm{PhD}$, when I was not supposed to pursue another course.
Yet, I am grateful for all these and more. I am grateful to have teachers whom did not drown me with unnecessary homework. I am grateful for teachers tolerating my questioning of authority and taking pleasure in out-questioning them. I am grateful for teachers that refused to stop my learning I asked for it. Most importantly, I am grateful to have teachers whom accepted me for who I am rather than deploying the entire machinery on me.

Since 2008, I had been a lecturer for almost half of that time and had been thinking about the current education/school system. Putting it bluntly, I am not satisfied with our current system - both as a student, and now as a lecturer/educator myself. "Judge a fish by its ability to climb trees and it will think it is stupid" [1]. Yet, the current system is doing exactly this with its test and examination system. This is made worse by having model answers and marking schemes. In the end, this system favours the best, most accurate, and fastest regurgitators - you are what you measure [2]. Little wonder that most of us forget everything after the exam. I was once told in a workshop that it takes extreme self-restraint for teenage 
students to sit in class for hours on end - it is against their biology. I add that such restraint is inhibitory to learning.

Making students sit in rows is really an assembly-line system [3]. Either a teacher assigned to a classroom and students flow in and out for lesson over a day or students stationed in designated classrooms and teachers coming in to deliver lessons - if we change the teacher to a robotic arm and the students to itemized parts; isn't that the view of a factory or manufacturing floor?

Before I bash down the current education/school system, we must ask ourselves - when did schools evolve into the schools today? Surely, Aristotle and Plato did not have to sit for hours in classes. In Analects [4], there was a passage where Confucius was discussing with four of his students regarding their aspirations. One of the students was even strumming a lute, only to stop when it was his turn to speak. The only reason I can think of is volume - the sheer volume of students, the commoditization of education. The demand for literacy and paper qualifications had seriously outstripped the supply for personalized education. Faced with a pipeline problem, the choice is either to limit the inflow or to increase the bandwidth.

Limiting the inflow appears to be impossible, as United Nations' Universal Declaration of Human Rights [5] (proclaimed on 10 December 1948 as General Assembly resolution 217A) enshrined the rights to education as Article 26; which states:

Everyone has the right to education. Education shall be free, at least in the elementary and fundamental stages. Elementary education shall be compulsory. Technical and professional education shall be made generally available and higher education shall be equally accessible to all on the basis of merit. Education shall be directed to the full development of the human personality and to the strengthening of respect for human rights and fundamental freedoms. It shall promote understanding, tolerance and friendship among all nations, racial or religious groups, and shall further the activities of the United Nations for the maintenance of peace. Parents have a prior right to choose the kind of education that shall be given to their children.

Hence, the only way seems to be increasing the bandwidth and we humans used the only system that we know - mass production
- the functional specialization and efficiency of Adam Smith [6]. As a result, all students ended up evaluated on a standardized metric without accounting for individual skills. Perhaps the analogy of evaluating all animals to climb trees is exaggerated as students are humans after all - one species. Nevertheless, a standardized evaluation does not account for the multi-faceted abilities of individual students.

It is true that every student requires foundational literacy and learning skills. After all, Plato's Academy was reputed to have an inscription that translates to "let no one ignorant of geometry enter my doors" [7]. Beyond that, when should we promote and celebrate individual skills and talents?

\section{Education versus teaching}

I believe that we must separate teaching from education. To teach is to flow knowledge from the teacher to student. The root Latin word for educate is educare, which means "lead out" or "bring out" [8]. Hence, teach and educate are of different direction of forces - one to push to students; one to pull from students. I believe that we must start with teach but end with educate. This is the spirit when Kevin Nicholas, my doctoral adviser, told me "Maurice, you are to start as my student but end as my colleague." The devil is then, how much or what proportion to teach and educate over time? I believe that we should aim for a logarithmic curve - rapid drop in teaching and rapid rise in education (Figure 1). The rate is then determined by the capabilities of the student. The primary purpose of education is constructing knowledge by challenging the students' mental model to failure (expectation failure) [9] so that they know the boundaries of each knowledge model, and to know the applicability of each model. If the only tool one has is a hammer, every problem is a nail.

\section{My Experience Learning Statistics}

It took me three attempts to learn statistics. The first two attempts were via teaching mode and I became more of a mechanistic calculator than a user of statistics. The third attempt succeeded because I was challenged on using what I learnt in my work; as such, I know why I learn it. Similarly, it is common experience that we learn much more and more enjoyable during graduate days than undergraduate days. I see graduate project as an anchor for the 
things I learn - I read with a purpose. And I have an adviser to emulate - the role model aspect.

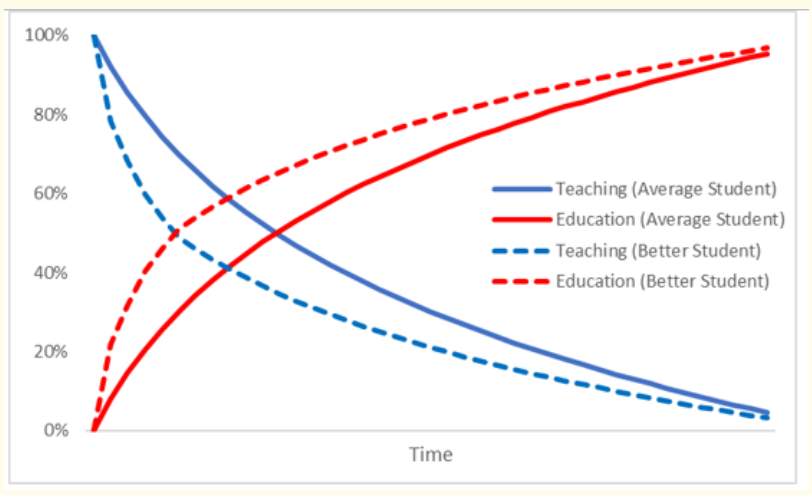

Figure 1: Changing ratio between teaching and education over time.

Can we change the current system towards this direction? I believe we can. And I venture to argue that the structures are already in place - we do not really have to come up with new frameworks but tweaking and re-deploying existing frameworks. How can we do it?

\section{Proposed apprenticeship/seminar system}

My suggestion is to use short and targeted workshops or seminar series for teaching and apprenticeship as the basis for education.

Apprenticeship is a common route to acquire in-depth skills in an area, as well as skills training required in the workforce [10], making apprenticeship a smooth transition from school to work. Many world-renowned chefs came through apprenticeship with chefs before them. In competitive sports, apprenticeship comes in the form of coach-trainee relationship. Physicians undergo apprenticeship under a registrar, whom in turn is apprenticed under a consultant. In formal academic setting, apprenticeship is most obvious during graduate programme where the adviser and candidate forms an apprenticeship relation. To me, the most valuable aspect of apprenticeship is the human relationship - mentor-mentee relationship and potentially close friendships between mentees [11]. It takes time for any person, both mentor and mentee, to open up to each other and this can take a long time, depending on personality traits. More often than not, this can take more than a semester. However, once the trust is built, the dividends are enormous. In academic world, academic genealogy has a deeper emotive aspect. This had even resulted in the Mathematics Genealogy Project (https://www.genealogy.math.ndsu.nodak.edu/), which inspired the creation of Academic Tree (https://academictree.org) - there is certain pride in knowing our academic ancestry. The use of the term "genealogy" is symbolic - it is symbolic of family.

Seminars are like lectures but are usually more compact and shorter in duration; hence, more targeted. I am in the view that most lecture systems, especially those 2-3 hours per week type of lectures, may not be as efficient as concentrated seminars. Perhaps I am affected by the two initial attempts at learning statistics, which were lecture-based. My third and final attempt was seminar-based - three seminars of 4-5 days each. Although intense, seminars are highly focused as I do not study several modules at the same time. It is just concentrated efforts on one module. In fact, a regular 3 hours per week over 10 -week lecture series can be done in 4 full days. In fact, this is the approach for many summer courses. Many graduate program employing external professors also use this structure. Of course, not all modules are suitable for this approach - I will not want to study a language this way.

Given that graduate programs are generally apprenticeshipbased and additional learning is done using seminars and/or lectures, how can we use this mixture in undergraduate? Nobody can propose a system suitable for every undergraduate program as there are many intricacies that must be considered. However, being in multiple roles (molecular biologist/biochemist, bioinformaticist/computational biologist, computer scientist, applied statistician, and data scientist), I believe that a mixed seminar/apprenticeship model may be possible in the fields that I am in.

For a four-year undergraduate program, the overall principle is stackable credentials [12]. The concept is to set a number of course hours or credit hours for various qualifications - diploma, advanced diploma, associate degree, bachelor degree, and so on. It is the undergraduate's responsibility, perhaps in discussion with an attached academic tutor, to clock the required number of cred-

Citation: Maurice HT Ling. "Science/Education Portraits V: The Scientific Tertiary Education that I had Envisioned". Acta Scientific Medical Sciences 2.8 (2019): 75-79. 
its based on interests and needs. The role of the academic tutor is to help the undergraduate to navigate available seminars and identify interests; hence, should have an overview of the undergraduate's learning route; thereby, acting in similar capacity as a career coach, which has the potential to result in increased student retention and graduation rates and also to higher job satisfaction after graduation [13].

On average, a typical American undergraduate degree will require about 130 credit hours. At 15-16 contact hours per credit hour, it works out to about 2,000 contact hours per undergraduate degree.

First year will consist of $100 \%$ teaching of 18 seminars, which is equivalent to 720 hours of lectures or contact. This should be sufficient to cover most of the fundamental topics. The means to clear each seminar can be by assignments. Assuming that the student has a week to finish the assignment, the student is effectively working a total of 198 days (72 days of seminars and 126 days working on assignments), which is only $55 \%$ of an entire year. Another method is to remove the distinction between full-time and part-time programs. This allows the student to clock the credits at their own pace. Better students can even opt for more seminars to attend. It may even be possible for cross-university seminar offerings.

Second year can be used to focus on building up foundation for advanced topics, which can cover 15 seminars. Using similar calculation, 600 lecture hours will be accumulated. Second year students should be encouraged to attend a combination of lunch time talks and half-day seminars to accumulate another 60 hours. The cumulative contact hours so far is 1380 . Yet, it leaves plenty of time for the student to explore apprenticeship options or even start apprenticeship. This also allows time for the student to explore other interest, especially those of interfacing disciplines. For example, a student interested in science communication can take several seminars on communication and writing while another student interested in multimedia education may take seminars on animation and educational pedagogy leading to development of educational animations.

The last two years should consist of 6 seminars per year, amounting to 240 contact hours per year, or about 70 days of teach- ing per year. This is in addition to 500 hours of apprenticeship per year. This will allow the student to develop a competency-based portfolio [14].

In total, this undergraduate program will have 1860 contact/ seminars hours and 1000 apprenticeship hours (or equivalent to 6 months of full time employment), which is sufficient to achieve technical skills beyond current undergraduate programs. Depending on the hour requirements, this also essentially meant that students can halt their program at different levels. For example, a student can complete the necessary requirements for an advanced diploma, go out to work for a few years before returning to stack more hours towards an associate degree or full bachelor's degree. That is the beauty of a stackable credentials - providing safety nets.

One of the major problems that I experienced in my own education is the number of wasted hours spent between classes and travelling. Full-day seminars will help to stem this wastage.

Of course, it is not to say that this structure is not without problems - the two most likely problems are from teaching and apprenticeship respectively. On teaching, issues with bandwidth is still present. Perhaps cross-institutional seminar offerings may help to elevate this problem. On apprenticeship, the most likely issue is on trust; specifically, the exploitation of trust and authoritative role of the mentor. A possible way to reduce this is by clear and multiple routes of redress through other academics, level coordinators, the Head of Department or to student services.

However, compared with the current system, I am not sure if this can be any worse. One thing for sure, I did recall telling my undergraduate roommate that if there is a program that is a good mixture of teaching and apprenticeship, I will go for it.

\section{Conflict of Interest}

The author declares no conflict of interest.

\section{Acknowledgement}

The author wishes to thank S. Aw and B. Peh for their comments on the drafts of this manuscript and the encouragement to submit this manuscript as a publication. 


\section{Bibliography}

1. M Kelly. "The rhythm of life: Living every day with passion and purpose". Simon and Schuster, (2004).

2. J Hauser and G Katz. "Metrics: You are what you measure!". European Management Journal 16.5 (1998): 517-528.

3. J Fischetti. "A different kind of teacher for a different kind of school". In Teacher Education in the 21st Century, Intech Open, (2019).

4. EB Brooks and AT Brooks. "The Original Analects: Sayings of Confucius and His Successors". Columbia University Press (1998).

5. L May. "United Nations Universal Declaration of Human Rights". in Applied Ethics, Routledge (2017): 54-57.

6. A Smith. An Inquiry into the Nature and Causes of the Wealth of Nations. A. \& C. Black, and w. Tait (1846).

7. DE. Smith, History of mathematics. Courier Corporation (1958).

8. S Amponsah., et al. "Lin's creative pedagogy framework as a strategy for fostering creative learning in Ghanaian schools". Thinking Skills and Creativity 31 (2019): 11-18.

9. K Bain. "What the best college teachers do". Harvard University Press (2011).

10. M Kuczera. "Striking the right balance: Costs and benefits of apprenticeship". OECD Education Working Papers (2017): 153.

11. MH Ling. "A personal narrative of 6 pre-university research projects over 7 years (2009-2015) yielding 19 manuscripts". MOJ Proteomics and Bioinformatics 6.3 (2017): 00193.

12. J Jones-Schenk. "Alternative Credentials for Workforce Development". The Journal of Continuing Education in Nursing 49.10
(2018): 449-450.

13. TR Tudor. "Fully integrating academic advising with career coaching to increase student retention, graduation rates and future job satisfaction: An industry approach". Industry and Higher Education 32.2 (2018): 73-79.

14. S Heeneman and EW Driessen. "The use of a portfolio in postgraduate medical education - reflect, assess and account, one for each or all in one?". GMS Journal for Medical Education 34.5 (2017): Doc57.

\section{Volume 2 Issue 8 August 2019 \\ C All rights are reserved by Maurice HT Ling.}

